\title{
Effects of first and second language on segmentation of non-native speech*
}

\author{
ADRIANA HANULÍKOVÁ \\ Max Planck Institute for Psycholinguistics, Nijmegen, \\ The Netherlands \\ HOLGER MITTERER \\ Max Planck Institute for Psycholinguistics, Nijmegen, \\ The Netherlands \\ JAMES M. MCQUEEN \\ Max Planck Institute for Psycholinguistics, Nijmegen, \\ The Netherlands \& Radboud University, Nijmegen, \\ The Netherlands
}

(Received: February 25, 2010; final revision received: May 29, 2010; accepted: September 1, 2010; First published online 11 July 2011)

\begin{abstract}
Do Slovak-German bilinguals apply native Slovak phonological and lexical knowledge when segmenting German speech? When Slovaks listen to their native language, segmentation is impaired when fixed-stress cues are absent (Hanuliková, McQueen \& Mitterer, 2010), and, following the Possible-Word Constraint (PWC; Norris, McQueen, Cutler \& Butterfield, 1997), lexical candidates are disfavored if segmentation leads to vowelless residues, unless those residues are existing Slovak words. In the present study, fixed-stress cues on German target words were again absent. Nevertheless, in support of the $P W C$, both German and Slovak listeners recognized German words (e.g., Rose "rose”) faster in syllable contexts (suckrose) than in single-consonant contexts (krose, trose). But only the Slovak listeners recognized, for example, Rose faster in krose than in trose ( $\mathrm{k}$ is a Slovak word, $\mathrm{t}$ is not). It appears that non-native listeners can suppress native stress segmentation procedures, but that they suffer from prevailing interference from native lexical knowledge.
\end{abstract}

Keywords: non-native segmentation, Slovak, German, Possible-Word Constraint (PWC), fixed stress

\section{Introduction}

Non-native listeners of a language often have the impression that native speakers of that language talk too quickly. The most obvious cause of this impression is difficulty in word segmentation. In order to understand spoken language it is essential to know where in the speech stream one word ends and another begins. While the process of segmenting the input into words is easily mastered in one's native language (L1), finding word boundaries in a non-native language (L2) is more difficult and remains demanding even after one has reached a high mastery of the L2. One reason for this difficulty could be that the perceptual system becomes specialized to deal with L1 input, and this specialization interferes with L2 speech processing. Consider a language in which each word onset carries main stress. In this case, L1 listeners could use stress as a cue to detect word boundaries. But

\footnotetext{
* This research was supported by a doctoral stipend from the Konrad Adenauer Foundation to Adriana Hanulíková and by the NWO SPINOZA grant awarded to Anne Cutler. We would like to thank Prof. Mária Vajićková for providing testing facilities in Bratislava, and Olinka Blauová for her help in finding Slovaks living in Berlin. We thank Katja Kühn for lending her voice to our materials. The lastlisted author is a member of the Behavioural Science Institute and the Donders Institute for Brain, Cognition and Behaviour, Centre for Cognition, both at the Radboud University Nijmegen.
}

when the same listeners then parse an L2 without this initial stress cue, the application of the L1 strategy might be of less use and could even hamper segmentation and consequently the recognition of L2 words. The question is this: Do L2 listeners keep their L1 segmentation mechanisms or can they learn a new, possibly more efficient, segmentation strategy for a given L2?

In this study, we therefore investigate the flexibility of the perceptual system with regard to segmentation of a non-native language. We will show that non-native listeners are influenced in segmentation by both L1 and L2 phonological knowledge, and hence we will argue that new segmentation procedures can be acquired later in life. At the same time, however, non-native listeners appear to be unable to prevent interference from the native language on non-native segmentation.

Numerous studies with native listener' populations have described segmentation as a by-product of lexical competition, which can be modulated by languagespecific, signal-driven cues (e.g., Norris et al., 1997). Most researchers meanwhile agree that lexical competition is the core mechanism of spoken word recognition (e.g., Gaskell \& Marslen-Wilson, 1997; McClelland \& Elman, 1986; Norris, 1994; for overviews see also Dahan \& Magnuson, 2006; Mattys, 1997; McQueen, 2007). This mechanism has received a great deal of empirical

Address for correspondence:

Adriana Hanulíková, Basque Center on Cognition, Brain and Language, Paseo Mikeletegi 69, 20009 Donostia, Spain

a.hanulikova@bcbl.eu 
support in several languages (e.g., Allopenna, Magnuson \& Tanenhaus, 1998; Cluff \& Luce, 1990; Connine, Blasko \& Titone, 1993; Connine, Blasko \& Wang, 1994; McQueen, Norris \& Cutler, 1994; Norris, McQueen \& Cutler, 1995; Tabossi, Burani \& Scott, 1995; Vitevitch \& Luce, 1998, 1999; Vroomen \& de Gelder, 1995; Zwitserlood \& Schriefers, 1995), and there is recent evidence that competition processes also occur when listeners are exposed to a non-native language (e.g., Marian \& Spivey, 2003a, b; Sunderman \& Kroll, 2006; Weber \& Cutler, 2004). In an eye-tracking study with Russian-English bilinguals, Marian and Spivey (2003a) presented participants with four objects on the screen, for example, a shovel (target English word: shovel), a shark (shovel's phonological English competitor: shark), a balloon (shovel's phonological competitor in Russian: sharik), and a pencil (a non-competing filler, English: pencil, Russian: karandash). Marian and Spivey reasoned that if Russian words are considered in parallel with English words during language processing in English, then proficient Russian speakers of English should show more looks to balloon than to pencil when following instructions such as "pick up the shovel". Russian listeners indeed made more looks to the balloon (Russian: sharik) as well as to the shark (shovel's English competitor: shark) compared to the unrelated distractor, the pencil (pencil), suggesting that Russians who are proficient users of English consider L1 Russian words as well as L2 English words during English word recognition. This result confirms that there is competition in bilinguals and, crucially, it suggests parallel activation of both languages. Word recognition thus seems to entail spurious activation of lexical candidates from both the native and the nonnative language. The extent to which this happens can be further affected by learner-related factors such as age of acquisition, proficiency, time spent in L2-speaking countries, or even the manipulation of the language mode during the experiment (e.g., Marian \& Spivey, 2003a; Sebastián-Gallés, Echeverria \& Bosch, 2005; Spivey \& Marian, 1999).

Lexical competition can be further modulated by language-specific knowledge about properties of the speech input (e.g., Norris et al., 1995; Vroomen \& de Gelder, 1995) such as stress or phonotactics. In an analysis of an English spoken corpus, Cutler and Carter (1987) found that over $90 \%$ of English content words begin with a strong syllable (i.e., a syllable with a full vowel). For English listeners, as proposed by the Metrical Segmentation Strategy (MSS; Cutler \& Norris, 1988), strong syllables are convenient segmentation points at which lexical initiation would be successful. Cutler and Norris showed that English listeners indeed segment speech more easily at strong syllables (containing a full vowel) than at weak syllables (containing a reduced vowel). A similar strategy appears to apply in Dutch
(Vroomen \& de Gelder, 1995, but see also Zwitserlood, Schriefers, Lahiri \& van Donselaar, 1993, on the role of syllables; and Quené \& Koster, 1998, showing no clear evidence for the MSS). In languages such as French, Catalan, and Spanish, speech segmentation seems to be based on syllables (e.g., Bradley, Sánchez-Casas \& García-Albea, 1993; Dumay, Frauenfelder \& Content, 2002; Mehler, Dommergues, Frauenfelder \& Seguí, 1981; Sebastián-Gallés, Dupoux, Seguí \& Mehler, 1992). In yet other languages with differing metrical properties such as Japanese, listeners have been shown to segment speech at mora boundaries (Cutler \& Otake, 1994; Otake, Hatano, Cutler \& Mehler, 1993; Otake, Hatano \& Yoneyama, 1996) because the rhythmic unit in Japanese is the mora.

These segmentation strategies learnt in the early years of life seem to influence the way that listeners segment speech in other languages: French listeners segment syllabically when listening to English (Cutler, Mehler, Norris \& Seguí, 1986), while English, Dutch, and Japanese listeners do not show syllabic segmentation in languages such as French (Cutler, 1997; Cutler et al., 1986, 1992; Otake et al., 1993, 1996). Similarly, when segmenting Japanese, neither English nor French listeners exploit the moraic cues to word boundaries (Cutler \& Otake, 1994; Otake et al., 1993).

It is less clear, however, whether new segmentation strategies can be acquired later in life and how they are used in a non-native listening situation. Indeed, although communication in a non-native language has become more a rule than an exception in today's world, most research on speech segmentation deals with the listener's ability to recognize words in their native language. Surprisingly little is known about how L2 listeners solve the segmentation problem online, and how they acquire cues to word boundaries (but see Altenberg, 2005; Cutler, Mehler, Norris \& Seguí, 1989; Golato, 2002; Sanders, Neville \& Woldorff, 2002; Sinor, 2006; and for a theoretical discussion, Carroll, 2004).

Since languages differ in their phonological structure, a simple transfer of native cues to a second language could hinder word recognition. A study by Weber and Cutler (2006) addressed this issue by looking at the segmentation cue provided by the phonotactic probabilities in English and in German. Their study used the word-spotting task, in which listeners were asked to respond whenever they found a target word embedded at the end of a nonsense sequence. Onsets of English words (e.g., lecture) were phonotactically either aligned with word boundaries (e.g., moinlecture, /nl/ signals a boundary, because it is not a legal syllable onset in either German or English) or were not aligned (e.g., gorklecture, the combination / kl/ does not force a boundary, because both languages allow words that start with $/ \mathrm{kl} /$ ). Both German and American participants found it easier to detect an English word such as lecture in the nonsense word moinlecture than in 
gorklecture. Weber and Cutler further examined whether German learners of English can use the knowledge of English phonotactics to help them detect English words, or whether they apply native German restrictions. Weber and Cutler found that highly proficient German learners of English performed better in thrarshlecture than in gorklecture, where both $/ \mathrm{fl} /$ and $/ \mathrm{kl} /$ are legal in German, but $/ \int 1 /$ is not a legal onset in English. Learners thus indeed effectively exploited phonotactic cues of the nonnative language in L2 speech segmentation. However, German listeners' responses were also facilitated when the boundary was signaled by German but not English phonotactics as in moycelecture (/s1/ is legal in English but not German onsets). Weber and Cutler concluded that L2-specific phonotactics can be acquired and efficiently used by L2 learners, but L1 knowledge remains active in non-native listening (see also Al-jasser, 2008, for a replication with Arabic speakers).

Not much is known about how flexible non-native listeners are in applying multiple segmentation cues in a non-native language. It could be that some segmentation cues are applied or suppressed more easily than others. We therefore tested how a lexical segmentation principle, which integrates lexical and sublexical sources of information, is applied in non-native segmentation. This principle is called the Possible-Word Constraint (PWC; Norris et al., 1997; Norris, McQueen, Cutler, Butterfield \& Kearns, 2001). It is based on lexical competition and operates in such a way that the continuous speech signal is segmented into words similarly across languages. The PWC proposes that the recognition probability of a word is smaller if, between this word and any likely word boundary, vowelless sequences such as single consonants remain. A likely word boundary can be signaled by a pause or by language-specific cues such as stress.

In line with this proposal, English listeners find it more difficult to recognize the word apple in fapple than in vuffapple (Norris et al., 1997), because the residue $f$ is vowelless, and hence disfavored, while the residue vuff contains a vowel. This segmentation principle has been replicated in typologically different languages such as Dutch (McQueen \& Cutler, 1998), Japanese (McQueen, Otake \& Cutler, 2001), Sesotho (Cutler, Demuth \& McQueen, 2002), and Cantonese (Yip, 2004). Although the simple dichotomy between vowelless and vowel-containing residues was sufficient to explain previous results from different languages, recent studies from Slovak and Berber reveal that under certain circumstances single consonants can be possible residues in the segmentation and recognition process (Cutler, El Aissati, Hanulíková \& McQueen, 2010; Hanulíková, McQueen, \& Mitterer, 2010).

In this paper, we further investigate the case of Slovak, a West Slavic language that allows words consisting solely of a single consonant, namely the four prepositions $k$ "to", $z$ "from", s "with", and $v$ "in". Each of these prepositions has a voiceless and a voiced positional allophone and each also has a vocalized form, e.g., /k/, /g/ and /ku/; $/ \mathrm{v} /$, /f/ and /vo/; etc. The vocalized form occurs when the following word has a similar place of articulation (e.g., zo zeme "from the earth"). Out of one million word tokens in the Slovenský národný korpus [Slovak National Corpus] (2007), 3\% are these single-consonant prepositions. Vocalized units form an additional $0.4 \%$ and are thus considerably less frequent. Prepositions are proclitic, thus combining phonologically with the following word (e.g., $v$ rane /vrane/ "in the wound"). However, orthographically they are always separated by a blank from the following noun or adjective (or other word classes) to avoid ambiguity in an otherwise phonetically ambiguous sequence such as /vrane/, representing $v$ rane "in the wound" or vrane "crow" + Dative inflection.

Thus, Slovak constitutes a challenge to the PWC, because listeners need to allow these words as possible words, even though they are vowelless. For this reason, Hanulíková et al. (2010) investigated how the segmentation of speech works in Slovak. In line with the PWC, Slovak listeners found it easier to recognize Slovak words such as ruka "hand" in nonwords with syllable residues (e.g., /dugruka/) than in nonwords with consonant residues (e.g., /truka/). Contrary to the predictions of the PWC, however, there was a difference in performance between different single-consonant contexts: If the single consonant itself could be a Slovak word (e.g., $\mathrm{g} / \mathrm{in} / \mathrm{gruka} /$, an allophone of the preposition $k$ ), then the word (e.g., ruka "hand") was spotted faster than when the consonant could not be a Slovak word (e.g., in/truka/). The results of this study suggest that single-consonant residues in Slovak are tolerated, but the necessary and sufficient condition for this tolerance is that the single consonant is an existing word in Slovak. Note that this study also ruled out that it is simply the short duration of the single consonant residues that triggers different segmentation performance from that observed with (longer) syllabic residues. In a further experiment, residues consisting of a single vowel, although short, were treated differently from consonantal residues: The single vowels were treated like longer syllables.

In addition to this language-specific application of the PWC in Slovak, another outcome of Hanulíková et al.'s (2010) study was that Slovak listeners seem to use fixed stress as a segmentation cue. The PWC depends and operates on signal-driven language-specific properties. Fixed stress is a prominent language-specific feature of Slovak (for more information on stress in Slovak, see Sabol, 1977; Sabol \& Zimmermann, 1994). It is not contrastive at the word level, that is, it is not used to distinguish one word from another (except rarely and only at the phrasal level; e.g., ZAhla som "I cheated" versus za HLAsom "following the voice", stressed syllable 
in upper case). Thus, stress has a demarcative function, and because its position correlates with word onsets, it is potentially useful for the segmentation of continuous speech (Trubetzkoy, 1939, p. 245). In Hanulíková et al.'s original Slovak recordings, all strings were produced with the canonical main stress on the first syllable of the string. This meant that the targets (e.g., ruka "hand") carried the main stress in the bisyllabic strings (e.g., TRUka) but not in the trisyllabic strings (e.g., DUGruka). Under these circumstances, Slovak listeners recognized the word ruka faster in truka than in dugruka. The second experiment suggested that this was an effect of fixed stress. After removing stress cues by cross-splicing, the results reversed and ruka was recognized faster in dugruka than in truka. Consistently across experiments, however, the target word ruka was recognized faster in gruka than in truka.

The use of single-consonant words and fixed stress appear to be specific properties of Slovak. Segmentation strategies dependent on the lexical status of single consonants and on fixed stress should thus apply to a language like Slovak. This raises the question whether L1 speakers of Slovak transfer these segmentation strategies to a second language. This is especially interesting if the L2 has neither single-consonant words nor fixed stress. German, for example, the second most frequently learned language by Slovak native speakers, is such a language. It does not allow single-consonant words and it exhibits lexical stress. German stress is less predictable with regard to position, and it is contrastive (e.g., überSEtzen "to translate" versus Übersetzen "to ferry across the river"). This then led to the following questions: Do proficient Slovak learners of German use the lexical status of single consonants in German and fixed stress when segmenting German speech? Or do they show flexibility in their choice of segmentation strategy as a function of the language they acquired later in life? How do Slovak listeners compare to German listeners when they segment German speech?

In two word-spotting experiments and one control lexical-decision task, we tested Slovak and German listeners' ability to recognize German words. In both word-spotting experiments, German words (e.g., Rose "rose") were embedded in three different contexts (as in Hanulíková et al., 2010) yielding nonsense sequences (e.g., suckrose, krose, and trose). As noted earlier, single consonants are not possible words in German, but in Slovak, $k$ "to" is a word while $t$ is not. Following previous studies on the PWC, we expected German listeners to spot words faster in the syllable context than in singleconsonant contexts, with no difference in performance between the two single-consonant contexts. If Slovak listeners to German have acquired enough phonological knowledge about German, they should resemble German native listeners in their performance. If, however, they apply Slovak segmentation procedures to the non-native input, we would expect a difference between the two single-consonant contexts, as in the Slovak results in Hanulíková et al. Thus, there should be faster responses to words embedded in possible Slovak prepositional contexts (krose) than in nonword contexts (trose). Further, since the recording procedure of the German material was kept comparable to the original Slovak experiment, the main stress was always on the first syllable of the whole sequence. For example, Rose carried a secondary stress in suckrose but primary stress in krose and trose. If Slovak listeners apply a fixed-stress segmentation strategy to German, just as they do in Slovak (see Hanulíková et al., 2010), there should be faster detection times for the target word Rose in single-consonant contexts (trose) than in syllable contexts (suckrose). However, if Slovak learners do not apply a fixed-stress segmentation strategy to German, then we should observe the reverse effect: faster detection of Rose in suckrose than in trose.

Interestingly, we could compare the use of two language-specific segmentation procedures. It could be that it is easier to adjust the use of stress in online speech segmentation than the use of lexical constraint concerning single consonants. Adjusting the use of stress would require flexibility at the sublexical level of processing. Prior research has shown that adult learners do not lose their ability in perceptual adjustments at the sublexical level. They can learn, for example, a new phonetic contrast after training (e.g., Tremblay, Kraus, Carrell \& McGee, 1997), and they can adjust the use of vowel duration in an L2 (e.g., Broersma, 2008). However, the acceptance of single consonants as viable residues might not show such flexibility, since such changes would require adjustments at the lexical level. Given prior studies on lexical activation of L1 as well as L2 words during second language listening (e.g., Marian \& Spivey, 1999, 2003a, b; Weber \& Cutler, 2004), the suppression of lexical cues in speech processing might be harder to achieve.

Whether Slovak learners apply their L1 segmentation strategies to German may also depend on their proficiency or on the amount of exposure to German. Therefore, we tested Slovak learners of German living in Germany (high exposure group) and Slovak learners of German living in Slovakia (low exposure group).

\section{Methods}

\subsection{Materials and design}

Forty-eight bisyllabic German words (nouns and verbs) with a strong-weak stress pattern were selected. All words started with a consonant. The material was selected carefully not to contain any additional German or Slovak content words. Each word was attached to three preceding contexts to yield three nonsense sequences per target. For example, the target word Rose "rose" was attached to a 
syllabic context (e.g., suckrose), to a prepositional singleconsonant context (e.g., krose), and to a non-prepositional single-consonant context (e.g., trose). Neither of these preceding single consonants is a possible word in German; however, /k/ is a Slovak word (the preposition "to"). As noted earlier, this manipulation is crucial for the evaluation of the non-native segmentation procedure. Therefore, the label "prepositional context" will refer to the phoneme $/ \mathrm{k} /$, which is a preposition in Slovak but not in German. The "non-prepositional" contexts included the consonants $/ \mathrm{p}, \int, \mathrm{t} /$, which have no meaning in either language.

The syllable contexts consisted of CVC syllables (e.g.,

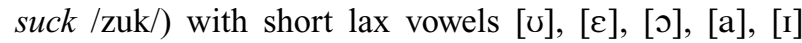
as nuclei. These syllables were not existing German or Slovak words, but fulfilled all phonological requirements for well-formed words, as the German and the Slovak lexicon contain monosyllabic words with short lax vowels (e.g., German Nuss /nus/ "nut"; Slovak les /les/ "forest"). The final consonants of these syllables were balanced so as to end equally often either with a prepositional or with a non-prepositional consonant. To allow for a close comparison with the previous Slovak study (Hanulíková et al., 2010), the same initial consonant clusters were chosen for both experiments with the condition that they exist in both languages. The consonant clusters in the onset of the bisyllabic nonsense sequences (e.g., /tr/ in trose) were thus always phonotactically legal in both German and Slovak.

The material was balanced for frequency of the lemma and onset consonant clusters, which were taken from the CELEX database (Baayen, Piepenbrock \& Gulikers, $1995)$ and were logarithmically transformed. The average log lemma frequency per million for the target words was 1.637 . The frequency of the onset consonant clusters was 3.063 for the prepositional consonant condition and 3.189 for the non-prepositional consonant condition. All experimental items are listed in the Appendix. Further, 102 nonsense words were constructed as fillers and attached to the same three types of preceding contexts. None of the filler words contained existing German or Slovak content words.

Three experimental lists were created containing all fillers in each list. Each target appeared in all lists, but in only one preceding context in a given list. Type of context was counterbalanced over lists so that each list had 16 targets in each type of context. Stimuli with preceding syllabic contexts were counterbalanced in such a way that half of the syllable contexts per list ended with a prepositional consonant and half with a non-prepositional consonant. The stimuli were compiled in a random order with one restriction that there was always at least one filler between two target-bearing items. A set of four additional target-bearing items along with nine fillers were used for a short practice session. Every participant was assigned to only one list.
The materials were read by a phonetically trained female native speaker of German who was not aware of the aim of the study. She received instructions to read the material at a normal speech rate and with main stress on the first syllable of the whole string. Intervocalic consonants were produced in an ambisyllabic way. The speaker read the items one by one, separated by a pause, in a clear citation style three times in a row. The recordings were made in a sound-proof booth on a Digital Audio Tape (DAT) at $48 \mathrm{kHz}$ sampling rate with 16-bit resolution. They were then re-digitized onto a computer and downsampled to $22.05 \mathrm{kHz}$. The stimuli were spliced into single speech files using the Praat speech editor (Boersma, 2001). There were no embedded schwas between the consonant clusters. All speech files were normalized so that their mean amplitude was approximately equal.

For a control lexical-decision task, which was conducted with German participants to exclude the possibility that any difference in performance could be due to pronunciation variation across conditions, all target words were carefully excised from the preceding contexts using the Praat editor. For example, the target word Rose was spliced out of the recording of suckrose, trose, and krose. For some onset clusters, it proved to be very difficult to determine clear-cut excision points; this was especially the case for $/ \mathrm{r}$ /-onsets. We used visual and auditory criteria to determine the onset of the first segment of the target, cutting at positive zero-crossings. For sequences in which phoneme boundaries could not be easily determined from the spectrogram, we chose a splicing point based on whether the previous phoneme was still audible in the remaining string. The same procedure was applied to the fillers. As in the word-spotting experiment, three experimental lists were used. These had the same order of target presentation as in the word-spotting task.

\subsection{Procedure}

The participants were tested separately in a quiet room. For the word-spotting experiments, they received written instructions in German that they would hear nonsense strings over headphones. Their task on each trial was to press a button whenever they spotted a real word embedded at the end of a nonsense string. For the lexicaldecision task, the written instructions for the participants stated that they would hear real German words and nonsense words over headphones. They were asked to press a response button if they thought the presented item was a German word. Participants were asked to respond as fast and as accurately as possible, and to say aloud each word they found. All experiments started after a short practice session. Participants heard the stimuli one at a time over headphones at a comfortable listening level. Slovak listeners were tested on their familiarity with the German target words after the experiment. If 
a participant was not familiar with a specific item (hence could not provide a description of the word meaning, a synonym or a translation equivalent), this item was excluded from further analysis for that given participant. Further, each participant was asked to fill in a language history questionnaire.

The presentation of the stimuli, timing, and the response time (RT) measurements were controlled by NESU (Nijmegen Experiment Set-Up). Each trial started with a $500 \mathrm{~ms}$ silence, after which the stimulus was presented. The time interval between the onsets of two successive trials was $4000 \mathrm{~ms}$ in both word-spotting experiments, and $3000 \mathrm{~ms}$ in the lexical-decision task. The subject's spoken responses were recorded on tape. All responses were monitored during the experiment and checked for correctness a second time using the recordings. Button-press responses accompanied by incorrect oral responses were discarded and counted as errors. The RTs were recorded from stimulus onset, but prior to the analysis were adjusted so as to measure from word offset by subtracting the total sequence duration.

\subsection{Participants}

Sixty-three native speakers of German and seventy-six native speakers of Slovak volunteered or received a small payment for their participation. All German participants were recruited from the Humboldt University in Berlin, 36 students participated in the word-spotting task and 27 in the lexical-decision task. None of the German students spoke Slovak, but 12 students reported knowledge of another Slavic language (Russian or Polish). Fifty Slovak participants were tested in Slovakia and were students of German at the Pedagogical Faculty of the Komenský University in Bratislava. The other twenty-six Slovak participants were living in Germany at the time of their participation in the study. They were either students at one of the universities in Berlin or were working in Berlin. All Slovak participants completed only the word-spotting task. All of them were proficient in German and had received an average of 10 years of formal training in German as a foreign language. The mean age of onset of acquisition of German was 10 years and the mean time period since they started learning German was 17 years. Their self-reported rating of their comprehension skills in German on a scale from 1 to 5 (where 1 was "very good" and 5 "not good") had a mean of 1.5. Learners were asked whether they felt confident in using German (1 meant "I agree" and 5 "I disagree"), and they reported a mean rating of 1.8. All participants either followed lectures in German or used German at work, and therefore could be considered to have high proficiency. With the exception of five participants, all Slovak learners of L2 German reported knowledge of at least one additional foreign language (e.g., English was reported by 64 participants).
Every participant took part in only one experiment and was assigned to only one experimental list. None of the participants reported any hearing difficulties.

\section{Results}

One German and two Slovak participants were excluded from further analyses because they missed more than $50 \%$ of all targets. In the German word-spotting task, one item (Wesen "being") was excluded from the analysis because it was missed by more than $2 / 3$ of all participants in one of the conditions. Seven items (Russe "Russian", Roggen "rye", Wesen "being", ruhen "to rest", rächen "to revenge", rennen "to run", räumen "to clear") met this criterion in the lexical-decision task and were excluded. Four items were excluded in the Slovak word-spotting experiment because the majority of participants reported not to be familiar with them (Russe "Russian", Roggen "rye", rühmen "to praise", rütteln "to shake"). The exclusion of these items did not alter the main pattern of results. The mean RTs as measured from word offset and the mean error rates (no response or response other than the intended word) were calculated per condition across subjects and items.

\subsection{L1 German listeners: Word-spotting task}

Mean RTs and error rates averaged across participants for each condition are displayed in Table 1. Responses to the target word were fastest when preceded by a syllable as compared to a prepositional consonant and a nonprepositional consonant. Repeated measures ANOVAs showed a main effect of context in the RT analysis $(F 1(2,68)=7.75, p=.001 ; F 2(2,92)=14.30, p<$ .001 ), but not in the error analysis (all $F \mathrm{~s}<1$, n.s.). In all analyses, we report Greenhouse-Geisser $p$-values, but the degrees of freedom are uncorrected.

Paired $t$-tests between the contexts revealed that spotting a word in the syllable context was significantly faster than in both the prepositional consonant context $(t 1(34)$ $=3.18, p=.003 ; t 2(46)=4.89, p<.001)$ and the nonprepositional context $(t 1(34)=3.67, p=.001 ; t 2(46)=$ $3.96, p<.001)$. There was no significant difference between the two single-consonant conditions (all $t \mathrm{~s} \leq$ 1.1, n.s.). A correlation analysis was then conducted to investigate whether the main effect obtained could be due to differing frequencies of the initial consonant clusters. There was a positive but not significant correlation between RTs for items in the single-consonant contexts and the consonant cluster $\log$ frequency $(\mathrm{R}=.09, p=$ .39), suggesting a robust effect of the main result.

\subsection{L1 German listeners: Lexical-decision task}

A control lexical-decision task was conducted to exclude the possibility that any difference in performance 
Table 1. German listeners: Mean RTs (in ms measured from word offset) and mean error rates.

\begin{tabular}{llll}
\hline \hline & \multicolumn{3}{c}{ Type of context } \\
\cline { 2 - 4 } & C preposition & C non-preposition & CVC syllable \\
\hline Word spotting & krose & trose & suckrose \\
Mean RT & 761 & 757 & 617 \\
Mean error & $12 \%$ & $13 \%$ & $12 \%$ \\
& & & \\
Lexical decision & $(\mathrm{k}) \mathrm{rose}$ & $(\mathrm{t})$ rose & (suck)rose \\
Mean RT & 317 & 292 & 303 \\
Mean error & $7 \%$ & $6 \%$ & $6 \%$ \\
\hline \hline
\end{tabular}

$\mathrm{C}=$ consonant $\mathrm{V}=$ vowel

observed in the word-spotting experiment could be due to pronunciation variation in targets across conditions. Therefore, in this control task, targets were presented without their previous contexts. If words taken from each of the word-spotting contexts were equally well recognizable, there should be no difference in reaction times between the three tokens of, for example, the word Rose "rose". As can be seen in Table 1, words excised from the three contexts were indeed recognized equally well. There was no main effect of context (i.e., context that has been removed from the target word) in either RTs $(F 1(2,52)=1.44, p=.25 ; F 2(2,80)=.64, p=.52)$ or in the error rate (both $F \mathrm{~s}<1$, n.s.).

A further statistical analysis was conducted to examine the main effect obtained in the German word-spotting task. To assess the word-spotting results taking the lexical-decision data as a covariate, a by-item linear regression was computed with the mean word-spotting RTs as the dependent variable and the lexical-decision RTs as the independent variable. The results of the regression analysis showed that word spotting was faster for words with short lexical-decision times $(\mathrm{R}=.36$, $t 2(1,122)=18.08, p<.001)$. The same procedure was used in a separate analysis of the error data, which revealed no significant result $(\mathrm{R}=.02, t 2(1,122)=.05$, $p=.82)$. An ANOVA was then run on the residuals of the regression. The main effect of context for the word-spotting experiment remained significant in the RT analysis $(F 2(2,80)=13.20, p<.001)$, and there was still no effect in the error analysis $(F 2(2,80)=.50$, $p<.61$ ). The main result obtained in the word-spotting experiment thus cannot be explained on the basis of acoustic differences among the targets in the different conditions.

Another analysis showed that the exclusion of the same items that were excluded from the lexical-decision experiment did not alter the pattern of results in the wordspotting experiment. In summary, neither the acoustic properties of the words nor the type of context from which they were excised differed across conditions in any way likely to have caused confounding effects on the main pattern of the word-spotting results. Clearly, German listeners make use of the knowledge about possible words while segmenting speech. None of the single-consonant contexts is a word in German, and this led to slower word recognition than in syllable (possible-word) contexts.

\subsection{L2 Slovak listeners: Word-spotting task}

In the second word-spotting experiment, Slovak L2 listeners of German were tested. If Slovak learners adjusted their non-native segmentation to the second language, they should perform similarly to German native listeners. As can be seen in Figure 1 and Table 2, Slovak learners of German recognized words faster and with fewer errors in the syllable context than in both singleconsonant contexts.

Repeated measures ANOVAs were conducted to examine the effects of preceding context and learner group. $2 \times 3$ ANOVAs were first conducted on the mean RTs and error rates over participants, with learner group as the between-participants factor (with two levels, high and low exposure group), and type of context as a withinparticipants factor (with three levels, as in Table 2). Although the group living in Germany (high exposure) tended to be descriptively faster and more accurate in all conditions (see Table 2), there were no significant interactions (all $F 1 \mathrm{~s}<1$, n.s.) and there was no main effect of learner group (all $F 1 \mathrm{~s}<1$, n.s.). Further analyses were therefore collapsed over all 74 Slovak participants.

There was a main effect of context in the RT analysis $(F 1(2,146)=60.29, p<.001 ; F 2(2,86)=31.15$, 
Table 2. Slovak learners: Mean RTs (in ms measured from word offset) and mean error rates.

\begin{tabular}{llll}
\hline \hline & \multicolumn{3}{c}{ Type of context } \\
\cline { 2 - 4 } & C preposition & C non-preposition & CVC syllable \\
\hline & krose & trose & suckrose \\
Learners overall $(\mathrm{n}=74)$ & & & 708 \\
$\quad$ Mean RT & 905 & 957 & $18 \%$ \\
$\quad$ Mean error & $22 \%$ & $21 \%$ & \\
Learners in Slovakia $(\mathrm{n}=48)$ & & & 722 \\
$\quad$ Mean RT & 931 & 966 & $19 \%$ \\
$\quad$ Mean error & $23 \%$ & $22 \%$ & 683 \\
Learners in Germany $(\mathrm{n}=26)$ & & & $16 \%$ \\
$\quad$ Mean RT & 858 & 939 & \\
$\quad$ Mean error & $21 \%$ & $18 \%$ & \\
\hline \hline
\end{tabular}

$\mathrm{C}=$ consonant; $\mathrm{V}=$ vowel
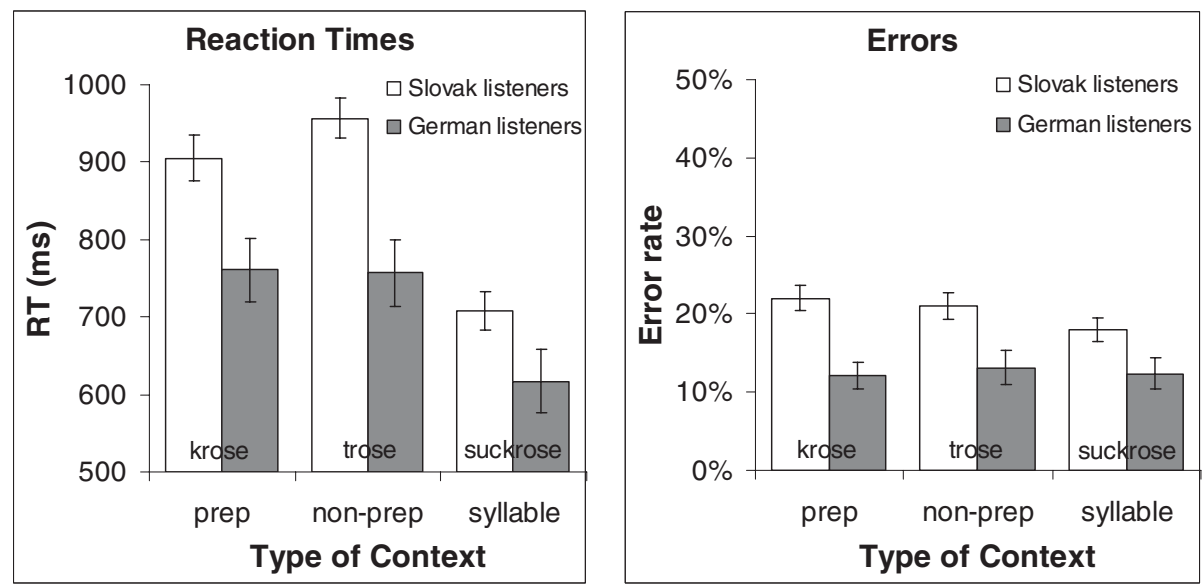

Prep = prepositional consonant; non-prep = non-prepositional consonant; syll = syllable

Figure 1. German and Slovak listeners: Word-spotting. Mean reaction times (RTs, measured in ms from word offset) and mean percentage of errors for Slovak and German listeners to German materials.

$p<.001)$ and, only for items, a main effect of context in the error analysis $(F 1(2,146)=2.28, p=.11 ; F 2(2,86)$ $=3.60, p=.03$ ). Paired $t$-tests (see Table 3 ) revealed that spotting a word in the syllable context was significantly faster and more accurate than in the prepositional context, and responses were also faster but not more accurate in the syllable context than in the non-prepositional context. There was also a significant difference between the two types of single consonants (by participants but not by items) in the RT analysis but not in the errors.

Unlike the previous Slovak results (Hanulíková et al., 2010), in which the native listeners' performance was slowest in the syllable condition when the target lacked primary stress, Slovak learners of German were fastest at recognizing German words when preceded by syllables as compared to single consonants. This was the case despite the lack of primary stress on German target words, suggesting that Slovak learners had attuned to German metrical structure. In addition, the earlier Slovak study observed the best performance in single prepositional consonant contexts. Although Slovak learners in the present study were faster at recognizing German words in the context including Slovak prepositions (krose) than the nonword consonant context (trose), the effect was attenuated (only marginally significant; only in the participants' analysis of RTs). Surprisingly, however, listeners were overall considerably slower in both consonant contexts than in the syllabic condition. This 
Table 3. Slovak learners: Paired t-test comparisons between the three types of contexts.

\begin{tabular}{lll}
\hline \hline & \multicolumn{2}{c}{ Dependent variables } \\
\cline { 2 - 3 } Comparisons & RT & Error \\
\hline Preposition vs. & $t 1(73)=2.21^{*}$ & $t 1(73)=.83$ \\
$\quad$ non-preposition & $t 2(43)=1.56$ & $t 2(43)=1.12$ \\
Preposition vs. & $t 1(73)=7.68^{* *}$ & $t 1(73)=2.12^{*}$ \\
$\quad$ syllable & $t 2(43)=6.08^{* *}$ & $t 2(43)=2.57^{*}$ \\
Non-preposition vs. & $t 1(73)=10.92^{* *}$ & $t 1(73)=1.31$ \\
syllable & $t 2(43)=7.78^{* *}$ & $t 2(43)=1.55$ \\
\hline \hline
\end{tabular}

${ }^{* *} p<.01 ;{ }^{*} p<.05$

result clearly differs from the native Slovak performance, suggesting that Slovak learners have adjusted how they segment non-native speech compared to their native speech, leading to results resembling German listeners. Having said that, however, a direct comparison of Slovak performance to that of German L1 listeners is necessary. The crucial comparison concerns the effect of context on response times between German and Slovak listeners.

\subsection{Comparison of Slovak and German listeners}

Figure 1 shows the mean RTs and mean error rates for both L1 and L2 listener groups. Although the overall RTs were slower and the overall error rates higher than those of the native German listeners, the relatively low error rate suggests that Slovak learners did not have difficulties spotting German words in nonsense sequences and hence were proficient enough to perform the word-spotting task.

Repeated measures ANOVAs were conducted to examine to what extent Slovak learners' performance resembles German listeners. The comparison of the German and Slovak experiments was betweenparticipants and within-items. The interaction between context and experiment was only marginally significant in the RT analysis $(F 1(2,214)=2.86, p=.06 ; F 2(2,84)=$ $2.73, p=.07$ ), and was not significant in the error rates (both $F \mathrm{~s}<1$, n.s.). There was a main effect of Experiment for RTs $(F 1(1,107)=12.9, p<.001 ; F 2(1,42)=81.32$, $p<.001)$ and error rates $(F 1(1,107)=17.85, p<.001$; $F 2(1,42)=35.48, p<.001)$. These results suggest that Slovak listeners were slower than German listeners, and that there was a tendency for the main pattern of results to differ across these two groups. Note that because the test of this interaction is a mixed comparison of betweenand within-participants factors, the statistical test has less power to detect a significant interaction. This difference shall be further analyzed below.

A correlation analysis of the learner data was conducted to assess whether the observed difference between the two single-consonant contexts could be explained by the frequency of consonant clusters in each condition determined by the Slovak frequency (taken from the Slovak National Corpus (Slovenský národný korpus, 2007)), German frequency (German frequency taken from CELEX), or by the sum of Slovak and German frequencies. The frequencies were higher for the prepositional clusters such as $/ \mathrm{kr}$ / (average Slovak $\log$ frequency 3.104; Slovak plus German log frequency 6.167) than for the non-prepositional clusters such as /tr/ (average Slovak log frequency 2.392; Slovak plus German $\log$ frequency 5.582). However, the reverse was the case if only the German cluster frequencies were considered (3.063 and 3.189, respectively). A correlation between RTs for items in the single-consonant contexts and the log cluster frequency per given item showed a positive and significant effect of Slovak cluster frequency $(\mathrm{R}=.26, p=$ $.01)$, Slovak plus German cluster frequency $(\mathrm{R}=.31$, $p=.004)$, and German frequency $(\mathrm{R}=.22, p=.04)$, suggesting that items with consonant clusters of higher frequency yielded longer RTs.

To assess the word-spotting results while taking the frequency of consonant clusters as a covariate, a byitem linear regression was computed with the mean word-spotting RTs as the dependent variable and the log frequency (Slovak, German, or both) as the independent variable. The same procedure was used in a separate analysis of the error data. In all cases, there was a significant positive correlation in both the RTs and the errors (see Table 4). Paired $t$-tests were then run on the residuals of these regression analyses. In the RT analysis of items, the effect between prepositional and non-prepositional consonant was statistically significant with Slovak frequency as a covariate $(t 2(43)=2.81, p=$ $.008)$ as well as with the Slovak plus German frequency as a covariate $(t 2(43)=2.26, p=.03)$. There was no significant difference between the two contexts with only the German consonant cluster frequency as covariate $(t 2(43)=1.08, p=.29)$. In the analysis of errors, again no significant results were obtained (all $t \mathrm{~s} \leq 1.4$, n.s.). It appears that the obtained RT effect is modulated by the consonant-cluster frequencies of the materials. Once the effects of these frequencies have been factored out, Slovak listeners were found to be significantly faster to detect German words in the prepositional context (krose) than in the non-prepositional context (trose).

Recall that one aim of this analysis was to evaluate the differences and similarities between the Slovak learners of German and the German L1 listeners. Previous ANOVAs showed a marginally significant interaction between Context and Experiment. To further explore this relationship, an additional $2 \times 2$ ANOVA was conducted with Experiment (Slovak learners and German listeners) and Context (prepositional and non-prepositional context) as factors. The ANOVA is based on the reported 
Table 4. Slovak learners: Regression analysis with cluster frequency as an independent variable.

\begin{tabular}{lll}
\hline \hline & \multicolumn{2}{c}{ Regression } \\
\cline { 2 - 3 } Independent variables & $\mathrm{RT}$ & Errors \\
\hline Slovak log cluster frequency & $\mathrm{R}=.26, t 2(1,86)=6.29^{*}$ & $\mathrm{R}=.31, t 2(1,86)=9.14^{* *}$ \\
German log cluster frequency & $\mathrm{R}=.22, t 2(1,86)=4.32^{*}$ & $\mathrm{R}=.11, t 2(1,86)=1.03^{*}$ \\
$\begin{array}{l}\text { Slovak log cluster frequency } \\
\text { + German log cluster frequency }\end{array}$ & $\mathrm{R}=.29, t 2(2,85)=3.76^{*}$ & $\mathrm{R}=.31, t 2(2,85)=4.57^{*}$ \\
\hline \hline & & \\
\hline${ }_{*}^{* *} p<.01 ;{ }^{*} p<.05$ & & \\
\hline
\end{tabular}

Table 5. Slovak learners: Main effects of context and interactions with learner-specific covariates.

\begin{tabular}{lll}
\hline \hline & \multicolumn{2}{c}{ ANCOVA } \\
\cline { 2 - 3 } Covariates & Main effect of context & Interaction with context \\
\hline Time spent in L2-speaking countries & $F 1(2,142)=52.02^{* *}$ & $F 1(2,142)=1.08$ \\
Overall error rate in the experiment & $F 1(2,144)=9.13^{* *}$ & $F 1(2,144)=.96$ \\
Time since onset of acquisition & $F 1(2,140)=14.74^{* *}$ & $F 1(2,140)=.33$ \\
\hline \hline
\end{tabular}

${ }^{* *} p<.01 ;{ }^{*} p<.05$

regressions with the Slovak and German consonantcluster frequency in the prepositional and the nonprepositional contexts over RTs for the two groups. There was no main effect of Experiment on the residuals with any of the frequency regressors (all $F \mathrm{~s}<1$, n.s.; note that the baseline difference in speed between German and Slovak participants is reflected in the intercept in the regression analysis). There was, however, a significant interaction between Context and Experiment with the Slovak frequency as the regressor $(F 2(1,42)=8.67, p$ $=.005)$, with the Slovak plus German frequency as the regressor $(F 2(1,42)=6.72, p=.01)$, but not with German frequency regressor alone $(F 2(1,42)=2.99, p=.09)$. This analysis shows that the performance of the two listener groups did clearly differ in the two consonantal conditions, when the influence of Slovak frequency or a combination of Slovak and German frequency has been factored out. We conclude that Slovak listeners seem to use their native knowledge about Slovak words while segmenting German.

In the final analysis, we took learner-specific variability into account. Previous research suggests that learnerrelated factors can affect L2 word recognition, among others age of acquisition, proficiency, and time spent in L2-speaking countries (e.g., Marian \& Spivey, 2003a; Sebastián-Gallés et al., 2005). To assess whether these factors also affect segmentation of non-native speech and indeed might have influenced the learners' performance in the present experiment, separate ANCOVAs were conducted with the following covariates: time spent in German-speaking countries, overall error rate in the experiment, and the number of years since onset of acquisition. The main effect of context remained significant in all these analyses and there were no significant interactions (see Table 5). Further, participants' self-ratings of general confidence in using German as a second language were taken as a factor (nine participants did not provide ratings on confidence). There was no significant interaction between the context and subjective ratings $(F 1<1$, n.s.), but there was a main effect of confidence ratings $(F 1(2,62)=5.13, p=.009)$. Participants with overall faster performance were those who were more confident in using German. These subjective ratings were thus positively correlated with faster processing of non-native speech.

\section{General discussion}

This study investigated the effects of first (Slovak) and second (German) language on segmentation of that second language. Slovak is a fixed-stress language that allows a limited group of single consonants to be words. These features of Slovak (fixed-stress and single-consonant words) have been previously shown to be used by native listeners of Slovak in L1-speech segmentation (Hanulíková et al., 2010). German, on the other hand, does not exhibit either of these features. This gave rise to the question whether Slovak learners of German apply their Slovak segmentation strategies to German speech or 
whether they show flexibility in which cues they use when listening to an $\mathrm{L} 2$.

As expected, German listeners segmented German speech following the Possible-Word Constraint. German listeners found it harder to recognize the word Rose "rose" in trose and krose (both $t$ and $k$ are vowelless and hence not possible words in German) than in the phrase suckrose (suck is also a nonword in German, but it is not a vowelless residue). There was no difference in reaction times between the two single consonants. This result provides further evidence that a single consonant, which itself cannot be a German word, is not a viable residue of the input and thus is disfavored as a parsing unit in German speech segmentation. The Possible-Word Constraint applies in German in the same way as in previously tested languages.

Slovak listeners resembled native German listeners in their segmentation of German: There was a clear advantage of syllables over single consonants as viable residues in both listener groups. This was different from the findings, with closely matched materials, in Slovak segmentation of Slovak speech (Hanulíková et al., 2010). This suggests that Slovak learners have suppressed native segmentation strategies to deal with German speech input. But we found a difference between single consonants as a function of their lexical status in Slovak. Since this effect was not visible in L1 German listeners, but resembles what was found in L1 Slovak listeners in Hanulíková et al.'s study, it suggests an influence of L1 knowledge on L2 segmentation.

A comparison of the present results with L1 Slovak listeners from Hanulíková et al.'s (2010) study leads to the conclusion that Slovak listeners do not use fixed-stress segmentation in German. In the present study, Slovak listeners to German showed responses to German target words with a secondary stress in the syllabic context faster than to words with a primary stress in consonant contexts. The opposite result was obtained in the earlier study with Slovak listeners to Slovak. Following prior research, segmentation procedures in one's native language are based on language-specific input properties (e.g., Cutler et al., 1992; see Cutler, 2005, for a review). But these studies also argue that bilinguals can recognize whether their particular segmentation procedures are appropriate in the second language and abandon them if they are not helpful (e.g., Cutler et al., 1992; Sanders et al., 2002, but see Golato, 2002). The acquisition of new segmentation procedures specific to the L2 should therefore be possible, and this suggestion is in line with the present results. Slovak learners have become attuned to the phonological properties of the non-native speech and are flexible enough to learn and choose the appropriate stress-based segmentation strategy.

Note that these differences in segmentation strategies across L1 and L2 make it unlikely that the observed effects in either case could result from the difference across conditions in the type of consonant preceding the target word. In the consonant conditions this was always an onset consonant (e.g., /k/ in krose), but in the syllable condition this was always a coda consonant (e.g., /k/ in suckrose). Although this difference was constant across experiments, performance changed (see Hanulíková, 2009, for further discussion and a study on syllabification in Slovak and German).

The flexibility that Slovak listeners have in dealing with stress, however, does not seem to be available when lexical constraints are used as a segmentation cue. Slovak learners show transfer from their L1 in terms of what they consider constitutes a viable residue. Slovak learners (and not German L1 listeners) treated single consonants as more or less acceptable residues depending on their status as viable residues in Slovak: Listeners found it harder to recognize the word Rose "rose" in trose ( $t$ being a nonword in Slovak) than in krose ( $k$ "to" being a word in Slovak). L1 lexical knowledge about viability of the speech input thus seems to influence segmentation in a second language. This effect resembles the Slovak results from Hanulíková et al.'s (2010) study. Those experiments revealed that vowelless sequences can be viable residues if they constitute a phonologically acceptable word in Slovak. However, the difference between non-prepositional consonants (e.g., $t$ ) and prepositional consonants (e.g., $k$ "to") was greater when Slovak listeners segmented Slovak speech compared to German speech in the current study. Additional analyses showed that frequency of consonant clusters (i.e., the frequency of $/ \mathrm{kr} /$ versus $/ \mathrm{tr} /$ ) modulated detection times. Although the frequencies of the consonant clusters were carefully matched within and between languages, an ideal cross-linguistic match was difficult to achieve; especially because it is not yet clear what factors are important in estimating the frequency of consonant clusters in an L2. Evidently, frequency counts based on native German speakers do not overlap with Slovak learners' usage of German. To a large extent, learners' frequencies might be determined by the L1 as well as by a subset of L2 (most likely the more frequent structures, which nevertheless might be representative for general consonant-cluster frequencies). Indeed, the covariance analyses showed that considering Slovak cluster frequency and the sum of Slovak and German frequencies strengthened the difference between prepositional and non-prepositional contexts.

In addition to frequency, another factor that might have led to the weaker effect between single consonants compared to the previous Slovak study is the combined influence of fine-grained acoustic-phonetic information and knowledge about L1 phonological processes. For example, although the phoneme $/ \mathrm{k} /$ occurs in both languages, the phonetic realization differs (e.g., plosives 
are not aspirated in Slovak, while they are in German). It is seldom the case, cross-linguistically, that two phonemes completely overlap in their realizations. Moreover, the realization of a preposition such as $k$ "to" in Slovak depends on the following context. The preposition $k$ is voiced when the following word starts with a voiced consonant or a sonorant and unvoiced otherwise. In the present experiment, $k$ was always embedded in a voicing environment, but it was never voiced. Because of phonotactic restrictions in German such an ideal match was not possible. For Slovak listeners, there was, hence, an available perceptual cue that might have (though not fully, as the results show) discouraged them from treating these consonants as viable residues.

If the lack of overlap between native and L 2 phonemic repertoire is crucial for the selective activation of language-specific phonological or lexical knowledge, there should not have been any difference between single-consonant contexts in the Slovak learner study; instead the results should have resembled the German L1 listeners, contrary to what was actually observed. Previous studies indicate that the lack of overlap in the phonemic representations of two languages might not necessarily reduce cross-language influence (see Strange, 1995, for an overview), as non-native perception is often inaccurate (e.g., Cutler, Weber \& Otake, 2006). Thus, the results of the present study strengthen the assumption that Slovak learners of German were influenced by Slovak phonological or lexical knowledge about acceptable parses, as the recognition of a word in the prepositional context was faster than in the non-prepositional context. The acoustic-phonetic details along with the frequency factor could have contributed to the overall weaker effect between the single-consonant contexts outlined above.

While Slovak learners appear to be influenced by their L1-driven lexical knowledge about the location of likely word boundaries, their stress-based segmentation procedures from their L1 seem not be applied in their L2. Why is this the case? Are some cues just easier to suppress than others? Previous research has shown that listeners are flexible in adapting to new cues (Cutler et al., 1992; Sanders et al., 2002). Sanders et al. (2002) argued that Japanese and Spanish proficient users of English apply the metrical segmentation strategy to segment English speech rather than their native mora- or syllable-based strategies. Weber and Cutler (2006) have also shown that German learners of English can use phonotactic constraints of their L2 English in speech segmentation. Less is known about the use of lexical cues in segmentation, and as the present results suggest, it may be harder to suppress the use of lexical knowledge in non-native segmentation.

These results have implications for the question whether there is a functional independence of L1 and L2 word recognition (e.g., Kroll \& de Groot, 1997; Paradis, 1997) or whether the L1 remains accessible in L2 word recognition (e.g., Dijkstra \& van Heuven, 1998, 2002; Green, 1998; Kroll \& Dijkstra, 2002; see also Brysbaert \& Dijkstra, 2006, for a review). Our results indicate that complete inhibition of the L1 during L2 processing does not seem possible. This converges with evidence from the word-recognition literature that a cross-language influence in bilingual processing occurs in non-native listening situations and appears to be sensitive to crosslinguistic phonological similarities (e.g., Doctor \& Klein, 1992; Marian \& Spivey, 1999, 2003a, b; Nas, 1983; Spivey \& Marian, 1999; for reviews, see Dijkstra 2005; Kroll \& Dussias, 2004; Sebastián-Gallés \& Kroll, 2003). Using the eye-tracking method, for example, Weber \& Cutler (2004) showed that, on hearing an English word (e.g., desk), native Dutch learners of English also more often looked at the distractor picture (e.g., of a lid, deksel in Dutch), apparently because of the phonological similarity between desk and deksel). English native listeners did not show such behavior. Similar results were observed with Russian-English bilinguals (Marian \& Spivey, 1999). These results from word-recognition studies indicate that non-native listening is hindered by greater competition than native listening is, and is influenced by native phonological knowledge. Although it is not possible to conclude from the present study whether the L1 lexical representations indeed competed with L2 words, because the task does not directly measure the recognition of Slovak prepositions, it seems that listeners nonetheless experienced influence from L1 phonological knowledge about likely word boundaries by treating single-consonant words as viable residues. This result indicates that Slovak words were activated during exposure to German speech.

Activation of L1 words during L2 word recognition has been previously shown in studies that manipulated the language mode during the experiment (e.g., the language of the instructions) or the general language preference of the participants (Spivey \& Marian, 1999). In the present study, the language of instruction was German, but the results nonetheless suggest that Slovak words were activated. Many of the participants lived in a Slovakspeaking environment and all participants knew that native knowledge of Slovak was a requirement for the study. Hence, more subtle experimental manipulations might be needed to understand fully the nature of non-native lexical processing as a function of language mode.

Previous studies have further indicated that the extent of cross-linguistic influence can be modulated by learnerrelated factors (e.g., Marian \& Spivey, 2003a; SebastiánGallés et al., 2005). The only learner-related feature in this study that positively correlated with processing speed in the L2 was participants' self-ratings of general confidence in using German as a second language. This means that those participants who felt confident in using German performed overall faster than those who felt less confident. 
In summary, the present results provide new evidence for how speech segmentation is mastered in a second language: L2 listeners can suppress stressbased segmentation procedures that they apply in their L1, because they would be inappropriate in L2 listening. Word boundary alignments signaled by viable residues, however, are modulated by L1 phonological knowledge about what constitutes a viable residue. These findings suggest that Slovak learners of German perhaps could mistakenly recognize the German word riechen "to smell" in kriechen "to crawl" because it would not be penalized strongly by the PWC; it is not misaligned with a likely word boundary, as $k$ is a viable residue in Slovak. Nevertheless, the recognition of words in syllabic contexts might be faster overall - as is appropriate for German speech. The word recognition and segmentation difficulties that bilingual listeners sometimes experience hence might result, at least in part, from influences of L1 knowledge during L2 speech segmentation.

\section{Appendix. Materials}

\begin{tabular}{llll}
\hline \hline & \multicolumn{3}{c}{ Context } \\
\cline { 2 - 4 } & \multicolumn{3}{c}{ Non- } \\
Target & Preposition & preposition & Syllable \\
\hline Rose "rose" & krose & trose & suckrose \\
Rätsel "riddle" & krätsel & trätsel & detträtsel \\
Reihe "row" & Kreihe & preihe & mockreihe \\
Liebe "love" & Kliebe & schliebe & kaschliebe \\
Russe "Russian" & Krusse & trusse & dettrusse \\
Rolle "role" & Krolle & schrolle & suschrolle \\
Räuber "robber" & kräuber & präuber & suckräuber \\
Roggen "rye" & kroggen & schroggen & jockroggen \\
Nummer "number" & knummer & schnummer joschnummer \\
Name "name" & Kname & schname & foschname \\
Nonne "nun" & knonne & schnonne & gocknonne \\
Nagel "nail" & knagel & schnagel & fucknagel \\
Nase "nose" & knase & schnase & jocknase \\
Nahrung "food" & knahrung & schnahrung mocknahrung \\
Lösung "solution" & klösung & plösung & fepplösung \\
Lampe "lamp" & klampe & plampe & gupplampe \\
Löwe "lion" & klöwe & schlöwe & seschlöwe \\
Linde "lime tree" & klinde & schlinde & gocklinde \\
Liste "list" & kliste & pliste & mockliste \\
Leute "people" & kleute & schleute & gockleute \\
Wesen "being, nature” kwesen & schwesen & goschwesen \\
Ware "goods" & kware & schware & lischware \\
Woche "week" & kwoche & schwoche & seschwoche \\
Wetter "weather" & kwetter & schwetter & schackwetter \\
\hline \hline & & \multicolumn{3}{c}{} \\
\hline
\end{tabular}

\begin{tabular}{llll}
\hline \hline ruhen "to rest" & kruhen & pruhen & guppruhen \\
rechnen "to count" & krechnen & trechnen & mockrechnen \\
rächen "to revenge" & krächen & trächen & jetträchen \\
retten "to rescue" & kretten & pretten & goppretten \\
rühren "to stir" & krühren & schrühren & suckrühren \\
rennen "to run" & krennen & schrennen & jockrennen \\
rühmen "to praise" & krühmen & prühmen & lupprühmen \\
liegen "to lay" & kliegen & schliegen & kaschliegen \\
lächeln "to smile" & klächeln & schlächeln & wucklächeln \\
löschen "to delete" & klöschen & plöschen & gopplöschen \\
nennen "to know" & knennen & schnennen & schacknennen \\
nutzen "to use" & knutzen & schnutzen & seschnutzen \\
leuchten "to shine" & kleuchten & pleuchten & mockleuchten \\
lenken "to steer" & klenken & plenken & fucklenken \\
räumen "to clear" & kräumen & präumen & feppräumen \\
rütteln "to shake" & krütteln & prütteln & jockrütteln \\
widmen "to dedicate" & kwidmen & schwidmen & mackwidmen \\
wohnen "to live" & kwohnen & schwohnen & schackwohnen \\
lachen "to laugh" & klachen & schlachen & deschlachen \\
wirken "to have an & kwirken & schwirken & joschwirken \\
effect" & & & \\
\hline \hline
\end{tabular}

\section{References}

Al-jasser, F. (2008). The effect of teaching English phonotactics on the lexical segmentation of English as a foreign language. System, 36, 94-106.

Allopenna, P. D., Magnuson, J. S., \& Tanenhaus, M. K. (1998). Tracking the time course of spoken word recognition using eye movements: Evidence for continuous mapping models. Journal of Memory and Language, 38, 419-439.

Altenberg, E. (2005). The perception of word boundaries in a second language. Second Language Research, 21, 325358.

Baayen, H., Piepenbrock, R., \& Gulikers, L. (1995). The CELEX Lexical Database (CD-ROM). Philadelphia, PA: Linguistic Data Consortium, University of Pennsylvania.

Boersma, P. (2001). Praat: A system for doing phonetics by computer. Glot International, 5, 341-345.

Bradley, D. C., Sánchez-Casas, R. M., \& García-Albea, J. E. (1993). The status of the syllable in the perception of Spanish and English. Language and Cognitive Processes, 8 (2), 197-233.

Broersma, M. (2008). Flexible cue use in nonnative phonetic categorization. Journal of the Acoustical Society of America, 123, 712-715.

Brysbaert, M., \& Dijkstra, T. (2006). Changing views on word recognition in bilinguals. In J. Morais \& G. d'Ydewalle (eds.), Bilingualism and second language acquisition, pp. 25-37. Brussels: The Royal Academies for Science and the Arts of Belgium.

Carroll, S. E. (2004). Segmentation: Learning how to "hear words" in the L2 speech stream. Transactions of the Philological Society, 102 (2), 227-254. 
Cluff, M. S., \& Luce, P. A. (1990). Similarity neighborhoods of spoken two-syllable words: Retroactive effects on multiple activation. Journal of Experimental Psychology: Human Perception and Performance, 16, 551-563.

Connine, C. M., Blasko, D. M., \& Titone, D. A. (1993). Do the beginnings of spoken words have a special status in auditory word recognition? Journal of Memory and Language, 32, 193-210.

Connine, C. M., Blasko, D. M., \& Wang, J. (1994). Vertical similarity in spoken word recognition: Perceptual ambiguity, sentence context and individual differences. Perception \& Psychophysics, 56, 624-636.

Cutler, A. (1997). The syllable's role in the segmentation of stress languages. Language and Cognitive Processes, 12, $839-845$.

Cutler, A. (2005). Lexical stress. In D. B. Pisoni \& R. E. Remez (eds.), The handbook of speech perception, pp. 264-289. Oxford: Blackwell.

Cutler, A., \& Carter, D. (1987) The predominance of strong initial syllables in the English vocabulary. Computer Speech and Language, 2, 133-142.

Cutler, A., Demuth, K., \& McQueen, J. M. (2002). Universality versus language-specificity in listening to running speech. Psychological Science, 13, 258-262.

Cutler, A., El Aissati, A., Hanulíková, A., \& McQueen, J. M. (2010). Effects on speech parsing of vowelless words in the phonology. Abstracts in Laboratory Phonology, 12, 115116. Albuquerque, New Mexico.

Cutler, A., Mehler, J., Norris, D. G., \& Seguí, J. (1986). The syllable's differing role in the segmentation of French and English. Journal of Memory and Language, 25, 385400.

Cutler, A., Mehler, J., Norris, D., \& Seguí, J. (1989). Limits on bilingualism. Nature, 320, 229-230.

Cutler, A., Mehler, J., Norris, D., \& Seguí, J. (1992). The monolingual nature of speech segmentation by bilinguals. Cognitive Psychology, 24, 381-410.

Cutler, A., \& Norris, D. (1988). The role of strong syllables in segmentation for lexical access. Journal of Experimental Psychology: Human Perception and Performance, 14, 113121.

Cutler, A., \& Otake, T. (1994). Mora or phoneme? Further evidence for language-specific listening. Journal of Memory and Language, 33, 824-844.

Cutler, A., Otake, T., \& McQueen, J. M. (2009). Vowel devoicing and the perception of spoken Japanese words. Journal of the Acoustical Society of America, 125, 1693-1703.

Cutler, A., Weber, A., \& Otake, T. (2006). Asymmetric mapping from phonetic to lexical representations in second-language listening. Journal of Phonetics, 34, 269-284.

Dahan, D., \& Magnuson, J. S. (2006). Spoken-word recognition. In M. J. Traxler \& M. A. Gernsbacher (eds.), Handbook of psycholinguistics, pp. 249-283. Amsterdam: Academic Press.

de Groot, A. M. B., \& Kroll, J. F. (eds.) (1997). Tutorials in bilingualism: Psycholinguistic perspectives. Mahwah, NJ: Lawrence Erlbaum.

Dijkstra, A. (2005). Bilingual visual word recognition and lexical access. In J. F. Kroll \& A. M. B. de Groot (eds.), Handbook ofbilingualism: Psycholinguistic approaches, pp. 179-201. Oxford: Oxford University Press.

Dijkstra, A., \& van Heuven, W. (1998). The BIA model and bilingual word recognition. In J. Grainger \& A. M. Jacobs (eds.), Localist connectionist approaches to human cognition, pp. 189-225. Mahwah, NJ: Lawrence Erlbaum.

Dijkstra, A., \& van Heuven, W. (2002). The architecture of the bilingual word recognition system: From identification to decision. Bilingualism: Language and Cognition, 5, 17597.

Doctor, E. A., \& Klein, D. (1992). Phonological processing in bilingual word recognition. In R. J. Harris (ed.), Cognitive processing in bilinguals, pp. 237-252. Amsterdam: Elsevier.

Dumay, N., Frauenfelder, U. H., \& Content, A. (2002). The role of the syllable in lexical segmentation in French: Wordspotting data. Brain and Language, 81, 144-161.

Gaskell, M. G., \& Marslen-Wilson, W. D. 1997. Integrating form and meaning. A distributed model of speech perception. Language and Cognitive Processes, 12, 613656.

Golato, P. (2002). Word parsing by late-learning French-English bilinguals. Applied Psycholinguistics, 23, 417-446.

Green, D. W. (1998). Mental control and the bilingual lexicosemantic system. Bilingualism: Language and Cognition, 1, 67-81.

Hanulíková, A. (2009). The role of syllabification in the lexical segmentation of German and Slovak. In S. Fuchs, H. Loevenbruck, D. Pape \& P. Perrier (eds.), Some aspects of speech and the brain, pp. 331-361. Frankfurt am Main: Peter Lang.

Hanulíková, A., McQueen, J. M., \& Mitterer, H. (2010). Possible words and fixed stress in the segmentation of Slovak speech. Quarterly Journal of Experimental Psychology, 63, 555-579.

Kroll, J. F., \& de Groot, A. M. B. (1997). Lexical and conceptual memory in the bilingual: Mapping form to meaning in two languages. In de Groot \& Kroll (eds.), pp. 201224.

Kroll, J. F., \& Dijkstra, A. (2002). The bilingual lexicon. In R. A. Kaplan (ed.), The Oxford handbook of applied linguistics pp. 301-321. Oxford: Oxford University Press.

Kroll, J. F., \& Dussias, P. (2004). The comprehension of words and sentences in two languages. In T. Bhatia \& W. Ritchie (eds.), Handbook of bilingualism, pp. 169-200. Oxford: Blackwell.

Marian, V., \& Spivey, M. (1999). Activation of Russian and English cohorts during bilingual spoken word recognition. In M. Hahn \& S. C. Stoness (eds.), Proceedings of the Twenty-first Annual Conference of the Cognitive Science Society, pp. 349-354. Mahwah, NJ: Lawrence Erlbaum.

Marian, V., \& Spivey, M. (2003a). Competing activation in bilingual language processing: Within- and betweenlanguage competition. Bilingualism: Language and Cognition, 6 (2), 97-115.

Marian, V., \& Spivey, M. (2003b). Bilingual and monolingual processing of competing lexical items. Applied Psycholinguistics, 24, 173-193. 
Mattys, S. L. (1997). The use of time during lexical processing and segmentation: A review. Psychonomic Bulletin \& Review, 4, 310-329.

McClelland, J. L., \& Elman, J. L. (1986). The TRACE model of speech perception. Cognitive Psychology, 18, 1-86.

McQueen, J. M. (2007). Eight questions about spoken-word recognition. In G. Gaskell (ed.), Oxford handbook of psycholinguistics, pp. 37-54. Oxford: Oxford University Press.

McQueen, J. M., \& Cutler, A. (1998). Spotting (different types of) words in (different types of) context. Proceedings of ICSLP 98, pp. 2791-2794. Sydney: Causal Productions.

McQueen, J. M., Norris, D., \& Cutler, A. (1994). Competition in spoken word recognition: Spotting words in other words. Journal of Experimental Psychology: Learning, Memory, and Cognition, 20, 621-638.

McQueen, J. M., Otake, T., \& Cutler, A. (2001). Rhythmic cues and possible-word constraints in Japanese speech segmentation. Journal of Memory and Language, 45, 103 132.

Mehler, J., Dommergues, J. Y., Frauenfelder, U. H., \& Seguí, J. (1981). The syllable's role in speech segmentation. Journal of Verbal Learning and Verbal Behaviour, 20, 298-305.

Nas, G. (1983). Visual word recognition in bilinguals: Evidence for a cooperation between visual and sound based codes during access to a common lexical store. Journal of Verbal Learning and Verbal Behavior, 22, 526-534.

Norris, D. (1994). Shortlist: A connectionist model of continuous speech recognition. Cognition, 52, 189234.

Norris, D., McQueen, J. M., \& Cutler, A. (1995). Competition and segmentation in spoken-word recognition. Journal of Experimental Psychology: Learning, Memory, and Cognition, 21, 1209-1228.

Norris, D., McQueen, J. M., Cutler, A., \& Butterfield, S. (1997). The possible-word constraint in the segmentation of continuous speech. Cognitive Psychology, 34, 191-243.

Norris, D., McQueen, J. M., Cutler, A., Butterfield, S., \& Kearns, R. (2001). Language-universal constraints on speech segmentation. Language and Cognitive Processes, 16, 637-660.

Otake, T., Hatano, G., Cutler, A., \& Mehler, J. (1993). Mora or syllable? Speech segmentation in Japanese. Journal of Memory and Language, 32, 258-278.

Otake, T., Hatano, G., \& Yoneyama, K. (1996). Speech segmentation by Japanese listeners. In T. Otake \& A. Cutler (eds.), Phonological structure and language processing: Cross-linguistic studies, pp. 183-201. Berlin: Mouton de Gruyter.

Paradis, M. (1997). The cognitive neuropsychology of bilingualism. In de Groot \& Kroll (eds.), pp. 331-354.

Quené, H., \& Koster, M. L. (1998). Metrical segmentation in Dutch: Vowel quality or stress? Language and Speech, 41, 185-202.

Sabol, J. (1977). Prozodická sústava slovenčiny [Prosodic system of Slovak]. Bratislava: Metodicko-výskumný kabinet Čsl. rozhlasu.
Sabol, J., \& Zimmermann, J. (1994). Komunikačný štatút prízvuku v spisovnej Slovenčine [Communicative status of stress in standard Slovak]. Prešov: Filozofická fakulta Univerzity P. J. Šafárika.

Sanders, L. D., Neville, H. J., \& Woldorff, M. G. (2002). Speech segmentation by native and non-native speakers: The use of lexical, syntactic, and stress-pattern cues. Journal of Speech, Language, and Hearing Research, 45, 519-530.

Sebastián-Gallés, N., Dupoux, E., Seguí, J., \& Mehler, J. (1992). Contrasting syllabic effects in Catalan and Spanish. Journal of Memory and Language, 31, 18-32.

Sebastián-Gallés, N., Echeverría, S., \& Bosch, L. (2005). The influence of initial exposure on lexical representation: Comparing early and simultaneous bilinguals. Journal of Memory and Language, 52, 240-255.

Sebastián-Gallés, N., \& Kroll, J. F. (2003). Phonology in bilingual language processing: Acquisition, perception and production. In N. O. Schiller \& A. S. Meyer (eds.), Phonetics and phonology in language comprehension and production, pp. 279-317. Berlin: Mouton de Gruyter.

Sinor, M. (2006). Lexical and phonotactic cues to speech segmentation in a second language. Ph.D. dissertation, University of Alberta, Edmonton. www.manuelsinor. com/links/ManuelSinor_thesis.pdf (retrieved February 15, 2009).

Slovenský národný korpus [Slovak National Corpus] (2007). prim-3.0-public-all. Bratislava: Jazykovedný ústav L'. Štúra SAV.

Spivey, M., \& Marian, V. (1999). Cross talk between native and second languages: Partial activation of an irrelevant lexicon. Psychological Science, 10, 281-284.

Strange, W. (1995). Speech perception and linguistic experience: Issues in cross-language research. Timonium, MD: York Press.

Sunderman, G., \& Kroll, J. F. (2006). First language activation during second language lexical processing. Studies in Second Language Acquisition, 28, 387-422.

Tabossi, P., Burani, C., \& Scott, D. (1995). Word identification in fluent speech. Journal of Memory and Language, 34, 440-467.

Tremblay, K., Kraus, N., Carrell, T. D., \& McGee, T. (1997). Central auditory system plasticity: Generalization to novel stimuli following listening training. Journal of the Acoustical Society of America, 102, 37623773.

Trubetzkoy, N. S. (1939). Grundzüge der Phonologie (Travaux du Cercle Linguistique de Prague 7).

Vitevitch, M. S., \& Luce, P. A. (1998). When words compete: Levels of processing in spoken word perception. Psychological Science, 9, 325-329.

Vitevitch, M. S., \& Luce, P. A. (1999). Probabilistic phonotactics and neighborhood activation in spoken word recognition. Journal of Memory and Language, 40, 374-408.

Vroomen, J., \& de Gelder, B. (1995). Metrical segmentation and lexical inhibition in spoken word recognition. Journal of Experimental Psychology: Human Perception and Performance, 21, 98-108. 
Weber, A., \& Cutler, A. (2004). Lexical competition in nonnative spoken-word recognition. Journal of Memory and Language, 50, 1-25.

Weber, A., \& Cutler, A. (2006). First-language phonotactics in second-language listening. Journal of the Acoustical Society of America, 119, 597-607.

Yip, M. C. W. (2004). Possible-word constraint in Cantonese speech segmentation. Journal of Psycholinguistic Research, 33, 165-173.
Zwitserlood, P., \& Schriefers, H. (1995). Effects of sensory information and processing time in spoken-word recognition. Language and Cognitive Processes, 10, 121136.

Zwitserlood, P., Schriefers, H., Lahiri, A., \& van Donselaar, W. (1993). The role of the syllable in the perception of spoken Dutch. Journal of Experimental Psychology: Learning, Memory, \& Cognition, 19, 260271. 